\title{
Salinity effects on germination of forage sorghumes
}

\begin{abstract}
Abstract: To investigate the effects of osmotic stress on forage sorghum (Sorghum bicolor L. Moench) varieties at critical stage of seed germination, i.e., at which salinization is initiated. A study was conducted at the Seed Technology Laboratory at University of Putra Malaysia (UPM- lab.) from October to November 2007. Two forage sorghum varieties (Speedfeed and KFS4) were evaluated in the salinity levels of $0,5,10,15 \mathrm{dS} \mathrm{m}-1$. The experimental design was Completely Random Design (CRD), which was based on factorial with 3 replications. In the experiment, seeds were germinated in covered, sterilized, disposable Petri dishes. Three parameters, namely germination percentage, germination rate, germination index and coefficient velocity of germination were estimated. The results of this study showed that different levels of salinity had significantly affected the germination percentage, germination rate germination index. In addition, a significant difference (1\%) was also found in the germination percentage between the two varieties. Meanwhile, the mean comparison of the treatments showed that the germination percentage in distilled water (S1) was the highest (92.5\%) and salinity dS m-1 (S4) had the lowest germination percentage. The maximum germination rate (35.58) and germination index (391.67) were retrieved from EC 0 and with the increasing salinity, these parameters were decreased. The evaluation of the two varieties showed that KFS4 (V1) had a higher germination percentage $(82.91 \%)$ than the speed feed $(72.5 \%)$. Consequently, the seed germination of KFS4 was better than the speed feed (in salty water and non-stress conditions). In other words, salt stress had been found to delay germination of both varieties.
\end{abstract}

Keyword: Salinity; Germination percentage; Germination index; Germination speed; Forage sorghum 